\title{
Personality, cognitive appraisal and labor pain
}

\section{BACKGROUND}

The theories focusing on the central neural mechanisms also pointed to the role of psychological factors in shaping painful sensations.

The aim of the study was to explore direct and indirect effects of personality and cognitive appraisal of childbirth on experienced labor pain.

\section{PARTICIPANTS AND PROCEDURE}

Labor pain was assessed twice by forty-five childbearing women aged 18-45 ( $M=28.31, S D=5.20 ; 23$ participants were primiparous): on admission to the obstetrics clinic and two days postpartum. On the first occasion, experienced and anticipated pain (VAS) and cognitive appraisal of labor (KOS) were measured, while the second assessment included rating of pain in the second stage of labor (VAS) and personality traits (NEO-FFI).

\section{RESULTS}

Mediation analyses indicated indirect effects of conscientiousness on pain at the first stage of labor via challenge appraisal and of neuroticism and conscientiousness on recalled second stage labor pain intensity via threat/loss appraisal. Irrespective of personality traits, correlations were found between pain and cognitive appraisal in terms of threat/loss and challenge.

\section{CONCLUSIONS}

The findings showed the importance of conscientiousness and positive appraisal of labor for diminishing the experienced and memory for labor pain. Such positive appraisals can be reinforced in prenatal classes or trained with the support of close persons.

\section{KEY WORDS}

personality traits; cognitive appraisal; labor pain; mediation

ORGANIZATION - University of Social Sciences and Humanities, Warsaw, Poland

AUthors' Contributions - A: Study design - B: Data collection - C: Statistical analysis - D: Data interpretation .

E: Manuscript preparation · F: Literature search · G: Funds collection

CORRESPONDING AUTHOR - Zuzanna Kwissa-Gajewska, Ph.D., University of Social Sciences and Humanities,

19/31 Chodakowska Str., 03-815 Warsaw, Poland, e-mail: zkwissa@swps.edu.pl

to Cite this ARticle - Kwissa-Gajewska, Z., \& Dołęgowska, M. (2017). Personality, cognitive appraisal and labor pain.

Health Psychology Report, 5(4), 304-313. doi: https://doi.org/10.5114/hpr.2017.67701

RECEIVED 29.04.2016 · REVIEWED 11.07.2016 · ACCEPTED 14.09.2016 · PUBLISHED 13.06.2017 


\section{BACKGROUND}

Childbirth can be an ambivalent experience in women's life. On the one hand, it is one of the most positive experiences for most of them (Simkin, 2000). On the other hand, it can be a source of stress. Women report concerns not only about the course of labor, but also about pain, characterized by many parturients as the worst pain they have ever experienced (Niven \& Murphy-Black, 2000).

Studies (cf. Taylor, 2012) have highlighted the role of culture-specific different expectations about pain and the course of labor in childbirth experiences. It is consistent with the model of stress proposed by Lazarus and Folkman (1984) postulating that it is the psychological cognitive appraisal of the event that determines both whether a given situation will be stressful and, consequently, the kind of stress response. Appraisal, referring to a distinctive evaluation of the significance of an event for the well-being of a person and adequacy of their resources for coping with it, mediates the effect of causal antecedents (e.g., dispositional traits) on the immediate and long-term stress outcomes (e.g., psychological well-being and physical functioning). Stressful events are appraised as threatening, challenging or harmful. Threat/loss appraisal was demonstrated to lead to negative outcomes - high levels of anxiety and depression (Chandler, Kennedy, \& Sandhu, 2007), a less salubrious cardiovascular response and worse performance than challenge appraisal (Blascovich, Seery, Mugridge, Norris, \& Weisbuch, 2004) associated with eustress (McGowan, Gardner, \& Fletcher, 2006).

On the other hand, cognitive appraisal itself is determined by characteristics of both the situation and the individual (personality traits) (Lazarus, 1991). Personality plays an important role in every aspect of human activity. The Five-Factor Model (Costa \& McCrae, 1992a), the most widely used framework in psychology (Maples, Guan, Carter, \& Miller, 2014), is composed of the following traits: neuroticism (a tendency to experience anxiety, angry hostility, depression, tending to be self-conscious, impulsive and vulnerable), extraversion (propensity to experience positive emotions, to be warm, sociable, assertive, active, a tendency to seek excitement), openness (a tendency toward fantasy, experiencing diverse emotions, to be aesthetic and creative, to have a wide range of interests), conscientiousness (a tendency to be self-organized, hard working, disciplined, achievement striving), and agreeableness (tending to be straightforward, subordinate, trusting and altruistic) (Costa \& McCrae, 1992a). A number of studies have indicated significant effects of the "Big Five" traits of neuroticism (N) and extraversion (E) on appraisal, coping behavior, emotions (Lee-Baggley, Preece, \& DeLongis, 2005) as well as mental and physical health (Maples et al., 2014; McCrae, 1990). The former trait (Payne, Seidman, Lung, Zelter, \& Tsao, 2013) predisposes to negative perception of difficult situations (Gunthert, Cohen, \& Armeli, 1999) and to negative emotions (Costa \& McCrae, 1992a), resulting in poorer psychological well-being, an exaggerated preoccupation with physical symptoms, and therefore greater symptom-related report bias (Watson \& Pennebaker, 1989) and somatic complaints (McCrae, 1990).

It should be noted that the Gate Control Theory (Melzack \& Wall, 1965), focusing on the central neural mechanisms, also pointed to the role of psychological factors in shaping painful sensations (Melzack, 1993): namely, perception (the meaning of symptoms, diverted attention), past experience, expectations, mood and behavior. According to Melzack's later concept of the "neuromatrix" (e.g. Melzack \& Katz, 2004), emphasizing the role that psychosocial factors can play in acute pain, the latter is a multidimensional experience produced by characteristic "neurosignature" patterns of nerve impulses generated by a widely distributed, genetically programmed, neural network in the brain (Melzack, 2001). The neuromatrix theory identifies three major sources of neural inputs that influence pain: sensory factors, cognitive-evaluative factors (memories of past experiences, attention, meaning, mood), and motivational-affective factors (the limbic system and associated homeostatic/stress mechanisms).

Reported research findings have partially confirmed the cognitive-transactional paradigm of stress (Lazarus \& Folkman, 1984), as well as the conclusions drawn by Melzack (Melzack \& Wall, 1963; Melzack \& Katz, 2004) concerning the role of psychological factors in pain outcomes. Namely, labor expectations were found to influence the course of labor, while anticipated pain (Ayers \& Pickering, 2005) and previous experience of pain (Niven \& Murphy-Black, 2000) affected the intensity of actual pain during labor. On the other hand, labor expectations may be modified by a number of psychosocial variables, including personality (neuroticism, Saisto, Salmela-Aro, Nurmi, \& Halmesmäki, 2001; trait anxiety, Ayers \& Pickering, 2005; anxiety sensitivity, Curzik \& Jokic-Begic, 2011; optimism, Guszkowska, 2014), number of childbirths (inconclusive results, Ayers \& Pickering, 2005), and childbearing women's age (Zasloff, Schytt, \& Waldenström, 2007).

While some studies on personality predictors of pain showed that neuroticism $(\mathrm{N})$ and extraversion (E) (cf. Ramírez-Maestre, Martínez, \& Zarazaga, 2004) were significant for pain sensation, others suggested that personality dimensions do not affect perceived pain (e.g. Wade, Dougherty, Hart, Rafii, \& Price, 1992). In this line, several studies report a significant relationship between neuroticism and acute pain. For example, positive relationships were found between
Personality, cognitive appraisal and labor pain 
neuroticism and intensity of pain: not only expected (Pearce \& Porter, 1983) and actual (Payne et al., 2013; Vassend, Røysamb, \& Nielsen, 2013), but also recalled (Raselli \& Broderick, 2007). Significant mediators of this relationship were catastrophizing (Goubert, Crombez, \& Van Damme, 2004) and anxiety sensitivity (Payne et al., 2013). Regardless of neuroticism level, similar associations were reported regarding trait anxiety (Ayers \& Pickering, 2005) and anxiety sensitivity with labor pain (Lang, Sorrell, Rodgers, \& Lebeck, 2006; Curzik \& Jokic-Begic, 2011), which may also suggest that painful sensations are intensified by the individual's tendency to experience anxiety. On the other hand, even in early research on relationships between personality and birth experience, extraversion was related to complaints of more severe pain during labor (Eysenck, 1961). This was contrary to Eysenk's suggestions (Lynn \& Eysenck, 1961) and later findings (Ruffle et al., 2015) that extroverts have higher pain thresholds than introverts. More recently, Brown and Johnston (2013) pointed out that scoring low in extraversion was associated with higher probability of having a caesarean section and experiencing complications during childbirth. No research findings have been reported as regards the role of the remaining Big Five personality traits in the formation of pain intensity. Personality traits appeared to influence the pain threshold independently, due to tendencies which represent an excessively negative cognitive and emotional orientation toward pain.

Another important issue related to labor pain is memory of noxious sensations, since it might be a source of positive and negative postpartum reactions (e.g. Niven \& Murphy-Black, 2000). The memory of labor pain may interfere with biochemical status, emotional state, pain experienced in postnatal days by women (Niven \& Murphy-Black, 2000), and overall childbirth experience (Waldenström \& Schytt, 2009). Researchers suggested that the accuracy of labor pain recall is questionable, but that the total experience was accurately recalled over long periods of time (Waldenström, 2003).

\section{CURRENT STUDY}

In the light of the presented theories and research findings it seems justified to examine the effect of higher-order personality traits on the expected, experienced, and recalled labor pain. On the grounds of Lazarus and Folkman's cognitive-relational theory of stress and the presented research review, it seems warranted to ask whether labor pain is influenced directly by relatively stable personality traits, or whether it is mediated by situational factors, such as cognitive appraisal of labor. Both threat/loss and challenge appraisals of labor are to be taken into consideration. Moreover, the study focuses on three as- pects of childbirth: the actual, expected, and recalled labor pain.

Based on the existing research and theory, the following research question was posed: are personality traits directly associated with expected and actually experienced pain in the first stage of labor as well as with pain in the second stage of labor recalled postpartum, or is that relationship indirect, through cognitive appraisal of childbirth?

Specifically, it was hypothesized that the effects of neuroticism on labor pain intensity (actual, expected and recalled) would be mediated by threat/ loss cognitive appraisal of childbirth. In spite of the limited number of studies and inconclusive data (concerning extraversion) or lack of studies on the role of other dimensions of personality in labor pain as measured by NEO-Five Factor Inventory (NEO-FFI), extraversion, openness, and conscientiousness were expected to predict less threat/loss and more challenge appraisal. Finally, it was hypothesized that threat/loss appraisal of labor would increase and challenge appraisal of labor would reduce actual, expected and recalled labor pain.

\section{PARTICIPANTS AND PROCEDURE}

\section{DESIGN AND SAMPLE}

The procedure of longitudinal data collection was completed in a sample of 45 women aged 18-45 years $(M=28.31, S D=5.20)$, with an uncomplicated pregnancy and no indications for caesarean section. Questionnaires on sociodemographic data, cognitive appraisal of labor, and experienced and expected pain were administered during the first stage of labor, i.e. on admission to the obstetrics clinic (T1). Personality characteristics and recall for the intensity of pain experienced during the second stage of labor were assessed two days postpartum (T2). The procedure had been accepted by the local Research Ethics Committee.

Among the study participants, $36(80.00 \%)$ were in a stable relationship, $41(91.10 \%)$ had at least a secondary education, and the majority were either employed or studying ( $55.60 \%$ and $28.90 \%$, respectively). Over a half of the participants $(51.10 \%)$ were primiparous, while $33.30 \%$ were second-time mothers, $13.30 \%$ third-time mothers, and $2.20 \%$ fourth-time mothers. In 7 cases $(15.60 \%)$ a caesarean section was performed.

\section{MEASURES}

Personality. The NEO-Five Factor Inventory (NEOFFI; Costa \& McCrae, 1992b) comprising 60 items was used to assess five personality dimensions: neu- 
roticism $(\mathrm{N})$, extraversion $(\mathrm{E})$, openness $(\mathrm{O})$, agreeableness (A), and conscientiousness (C). Each of the questionnaire items was rated on a 5-point scale ranging from 1 (I definitely disagree) to 5 (I definitely agree). The higher the score on a particular subscale, the higher is the intensity of the personality trait measured. Due to the duration of assessment and specificity of the labor situation, this personality measurement was conducted after the delivery, at T2. Cronbach's $\alpha$ coefficients for particular subscales ranged from $.68(\mathrm{~A})$ to $.82(\mathrm{C})$.

Cognitive appraisal. The 35-item Stress Appraisal Questionnaire - KOS (Włodarczyk \& Wrześniewski, 2010) was used for the measurement of cognitive appraisal of childbirth. Two types of appraisal were taken into account, in terms of either threat/loss (e.g. I feel frightened by the situation; 10 items), or challenge (e.g. I feel mobilized by the situation; 7 items). Each item was rated by the respondent on a 4-point scale, from 1 (No, definitely not) to 4 (Yes, definitely so). The higher the score on a given subscale, the stronger is the respondent's tendency to this particular type of situational appraisal. Cronbach's $\alpha$ coefficients were .75 for challenge and .83 for threat/loss appraisal.

Labor pain. A 10-centimeter visual analog scale (VAS) was used for labor pain severity assessment on a scale from 0 (no pain) to 10 (worst possible pain). Labor pain was measured on admission (T1): the actually experienced (How much pain do you experience now?) and expected pain (How much pain do you expect to experience during delivery?). Recall of the second stage labor pain was rated up to $48 \mathrm{~h}$ after delivery (T2): (How much pain have you experienced during delivery?).

\section{STATISTICAL ANALYSIS}

To answer the research question posed in the study, two parallel multiple mediation models were tested using a bootstrapping procedure (Hayes, 2013). Shrout and Bolger (2002) recommend bootstrapping when the sample size is small and the sampling distribution is not normal (Preacher \& Hayes, 2008).

The total indirect effect (the sum of indirect effects across mediators in a certain model), as well as the specific indirect effect (the indirect effect of a particular mediator) were examined. If the $95 \%$ bias-corrected and accelerated confidence interval (BCA) for the parameter estimate did not contain zero, then the indirect effect was statistically significant at the .05 level and mediation was demonstrated (Preacher $\&$ Hayes, 2008). The possibility of parallel-serial testing of several potential mediators is the advantage of this method.

As regards the research question, separate multiple mediation analyses for pain expected and experi- enced on admission (T1) and the recalled second stage pain (T2) were conducted. The models included personality dimensions (T2) and cognitive appraisal (T1).

In addition, the model for recalled second stage pain included actual pain experienced at $\mathrm{T} 1$.

\section{RESULTS}

Prior to mediation analysis, descriptive statistics and simple correlations between variables (at T1 and T2) were calculated (see Table 1).

Out of all the personality traits under study, only neuroticism and conscientiousness were associated with cognitive appraisal of labor and with labor pain. Neuroticism was positively correlated with threat/loss appraisal and increased pain (at T1 and $\mathrm{T} 2$ ), while conscientiousness correlated with more marked challenge appraisal and less threat/loss (T1) and increased second stage labor pain recall (at T2). Expected pain (at T1) was correlated only with cognitive appraisals of either type (challenge and threat/ loss), but was not correlated with personality traits, and was therefore excluded from further analysis.

A one-way analysis of variance for repeated measures indicated that labor pain perceived at $\mathrm{T} 1$ and $\mathrm{T} 2$ (Table 1) differed significantly, Wilks' $\lambda F(1,43)=6.92$, $p=.012$. Moreover, pain experienced in the first stage of labor (T1) and recalled second stage labor pain (T2) were significantly more intense than the expected pain, Wilks' $\lambda F(1,43)=178.67, p<.001$, and Wilks' $\lambda F(1,43)=206.55, p<.001$, respectively.

Significance of sociodemographic variables for dependent variables was also tested: none of the subsidiary variables such as age, education level ( 0 - primary/vocational education, 1 - college/university), marital status, number or previous births $(0$ - primiparous women, 1 - multiparous women), or natural childbirth/cesarean section ${ }^{1}$, had a significant effect on either the experienced (at T1), expected (at T1) or recalled second stage pain (at $\mathrm{T} 2$ ).

\section{EFFECTS OF PERSONALITY TRAITS ON LABOR PAIN: CROSS-SECTIONAL ANALYSES}

To test the total and specific indirect effects of personality traits $(\mathrm{N}, \mathrm{E}, \mathrm{O}, \mathrm{A}, \mathrm{C})$ on labor pain at the first stage (T1) and recall of second stage labor pain (T2) as mediated by cognitive appraisal, multiple mediation analyses were conducted.

Results of the bias-corrected bootstrapping procedure revealed that the indirect effect of conscientiousness on pain at $\mathrm{T} 1$ was significant (indirect effect coefficient $=-.03, S E=.01$ ) and statistically different from zero, 95\% CI $=[-.05,-.01]$ (see Figure 1). The indirect effect via challenge appraisal had a negative sign, $\beta=-.02, S E=.01,95 \% \mathrm{CI}=[-.06,-.00]$.
Personality, cognitive appraisal and labor pain 


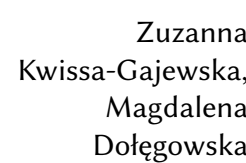

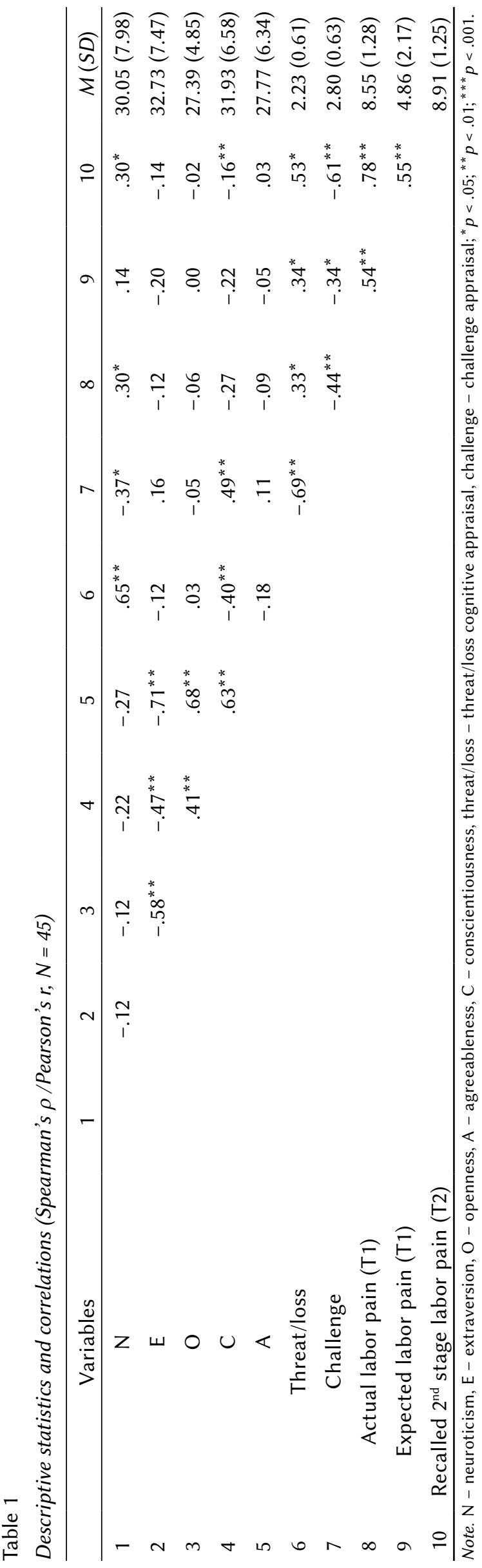

As the total effect was significant, $c=-.04, p=.033$, and the direct effect was non-significant, $c^{\prime}=-.01$, $S E=.16, p=.444$, full mediation was observed. The model explained $16.80 \%$ of the variance of labor pain at T1.

The remaining direct and indirect (respectively) effects on actual pain at T1 were not significant (neuroticism, $\beta=.03, S E=.04, p=.451 ; \beta=.03, S E=.03$, $95 \% \mathrm{CI}=[-.02,08]$, extraversion, $\beta=.00, S E=.03$, $p=.991 ; \beta=-.01, S E=.02,95 \% \mathrm{CI}=[-.05, .02]$, openness, $\beta=-.03, S E=.05, p=.527 ; \beta=.01, S E=.03,95 \%$ $\mathrm{CI}=[-.04, .07]$, and agreeableness, $\beta=-.03, S E=.02$, $p=.255 ; \beta=-.00, S E=.06,95 \% \mathrm{CI}=[-.04, .02])$.

Analyses of the effects of personality traits on recalled second stage labor pain indicated that only neuroticism, $\beta=.05, S E=.02,95 \% \mathrm{CI}=[.01, .11]$ (Figure 2) and conscientiousness, $\beta=-.01, S E=.01$, $95 \% \mathrm{CI}=[-.04,-.00]$ (Figure 3 ) were (indirectly) linked with this recall. Both the total effect $(\mathrm{N}: \beta=.02$, $S E=.02, p=.341 ; \mathrm{C}: \beta=-.03, S E=.01, p=.062)$ and the direct effect $(\mathrm{N}: \beta=-.03, S E=.03, p=.254$; C: $\beta=-.01, S E=.01, p=.431$ ) were not significant, and full mediations were observed. Only threat/ loss appraisal mediated these effects (for $\mathrm{N}: \beta=.05$, $S E=.03,95 \% \mathrm{CI}=[.01, .10]$; for $\mathrm{C}: \beta=-.01, S E=.01$, $95 \% \mathrm{CI}=[-.03,-.00])$. The model for $\mathrm{N}$ explained $63 \%$ of the variance of labor pain recall at $\mathrm{T} 2$, and the same effect was obtained for the $\mathrm{C}$ model. For extraversion $(\beta=-.00, S E=.02, p=.828 ; \beta=.01$, $S E=.01,95 \% \mathrm{CI}=[-.04, .01])$, openness $(\beta=.00$, $S E=.03, p=.897 ; \beta=.01, S E=.02,95 \% \mathrm{CI}=[-.02, .06])$ and agreeableness $(\beta=.01, S E=.02, p=.590 ; \beta=-.01$, $S E=.01,95 \% \mathrm{CI}=[-.02, .01])$, both direct and indirect effects, respectively, on recalled second stage labor pain were not significant.

\section{DISCUSSION}

The purpose of the study was to analyze relationships of personality traits with labor pain, taking into account a possible mediating role of cognitive appraisal of labor. Generally, the results indicated a crucial role of neuroticism, conscientiousness, and cognitive appraisal for the actual and recalled labor pain.

In the first step of the analysis pain was found to increase over successive stages of labor. Interestingly, the level of expected labor pain was significantly lower than that of pain actually experienced in the first stage of labor and of the recalled second stage labor, even though the women suffered considerably more severe pain at the time of making predictions. This finding support the idea that expectations of childbirth could be more affected by social attitudes ('common knowledge') than by actual experiences during labor (Terry \& Gijsbers, 2000). Underpredicted pain may in turn hurt more than correctly predicted pain (Arntz, 1996), which is 


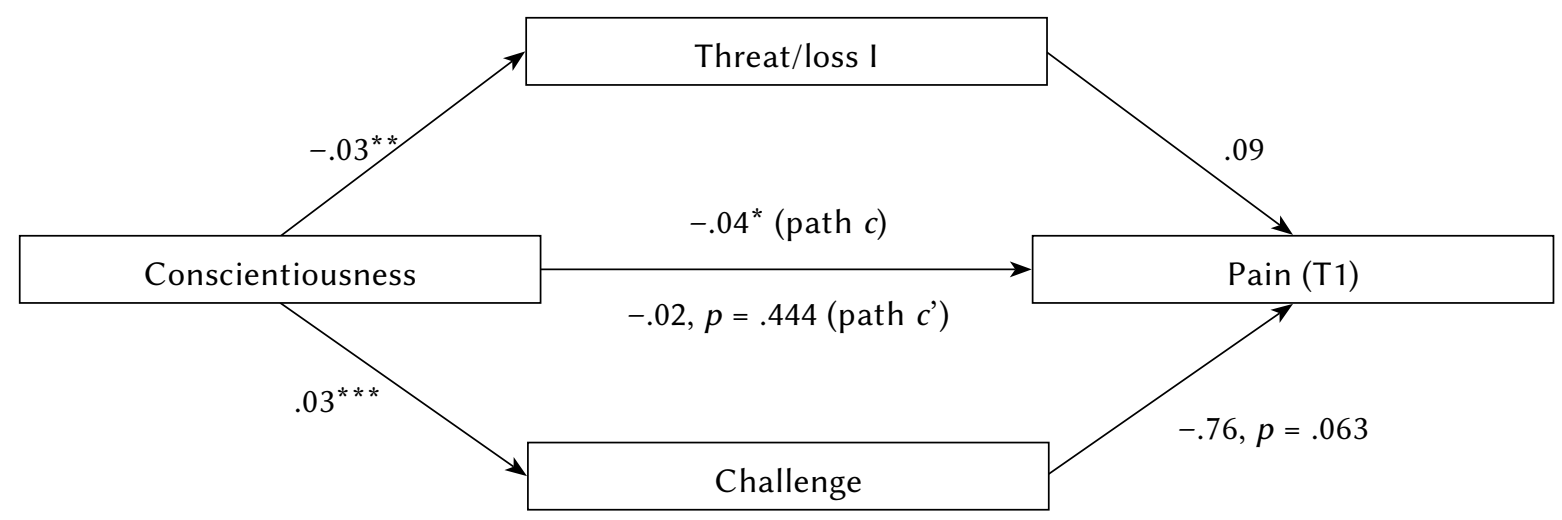

Note. ${ }^{*} p<.05 ;{ }^{* *} p<.01 ;{ }^{* * *} p<.001$. Values presented are unstandardized coefficients.

Personality, cognitive appraisal and labor pain

Figure 1. The effect of conscientiousness on pain at T1. Results of multiple mediation analysis.

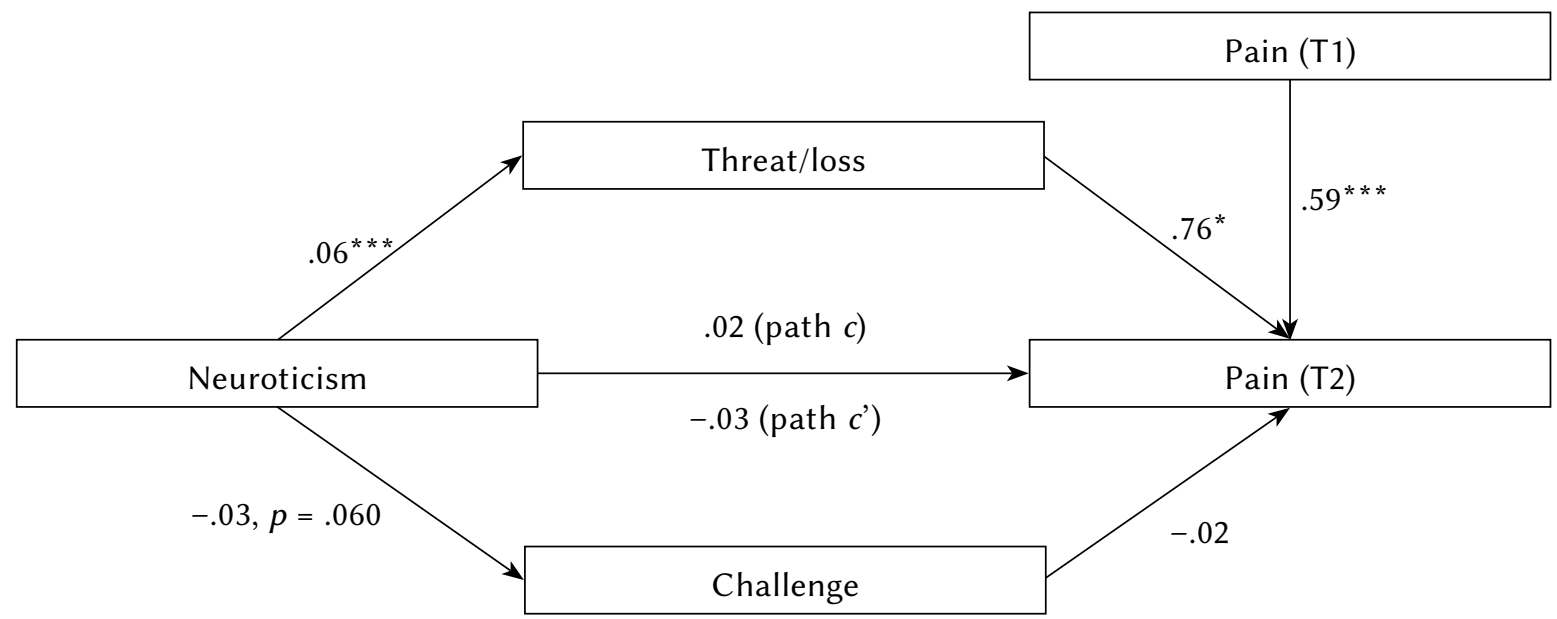

Note. ${ }^{*} p<.05 ;{ }^{* *} p<.01 ;{ }^{* * *} p<.001$. Values presented are unstandardized coefficients.

Figure 2. The effect of conscientiousness on recalled second stage labor pain (T2). Results of multiple mediation analysis with pain at $\mathrm{T} 1$ as a covariate.

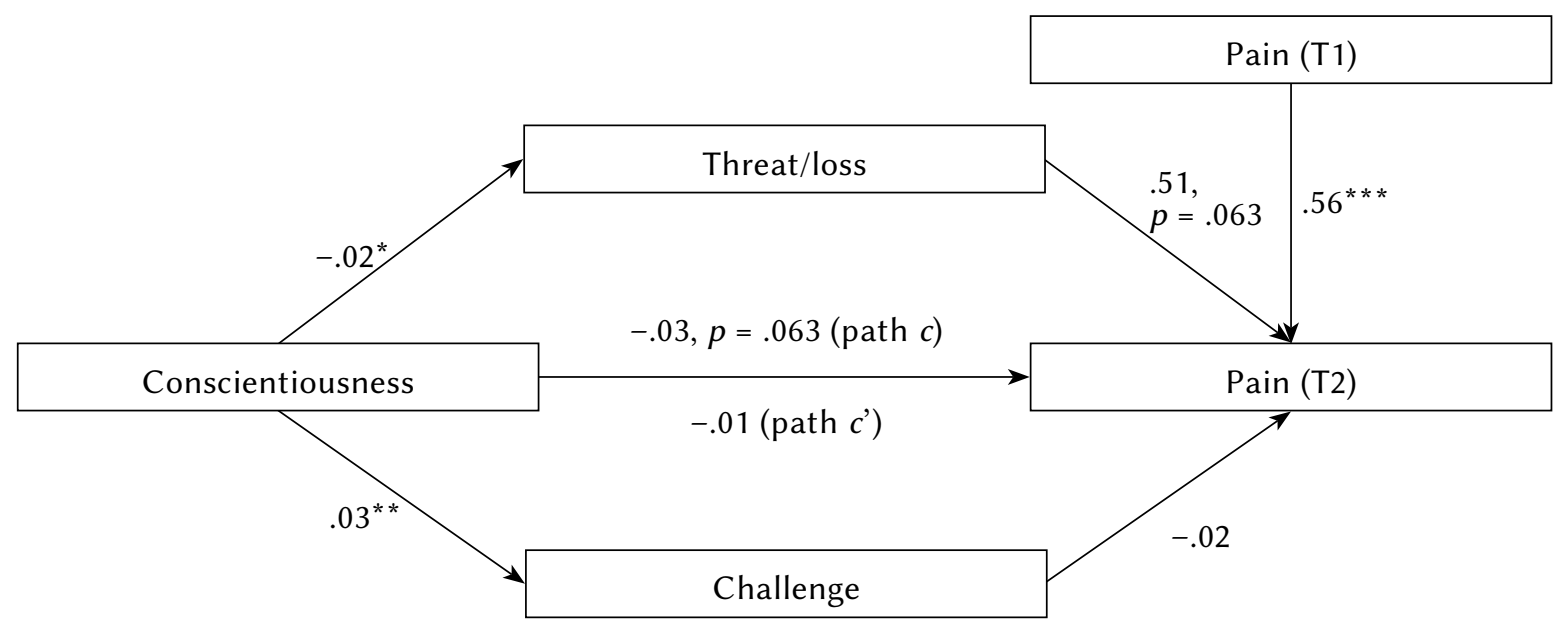

Note. ${ }^{*} p<.05 ;{ }^{* *} p<.01 ;{ }^{* * *} p<.001$. Values presented are unstandardized coefficients.

Figure 3. The effect of neuroticism on recalled second stage labor pain (T2). Results of multiple mediation analysis with pain at $\mathrm{T} 1$ as a covariate.

explained by extra aversiveness of underpredictions or by threat resulting from denial of the possibility of pain severity.
The obtained correlations of neuroticism with cognitive appraisal and pain were in accordance with the psychological properties of this personality trait. 
Neuroticism as a tendency toward emotional distress was associated with an increase of threat/loss appraisal and in a decrease in challenge appraisal, which corroborated earlier research findings (Gunthert et al., 1999; Schneider, Rench, Lyon, \& Riffle, 2011). The confirmed positive association of neuroticism with pain (Pearce \& Porter, 1983) may be explained by the fact that this personality trait lowers the threshold at which pain is perceived as threatening (Goubert et al., 2004). Higher neuroticism is also known to result in better recall of pain unpleasantness (Lefebvre \& Keefe, 2013).

Conscientiousness has been explored in a few studies on labor pain (Johnston \& Brown, 2013). The effect of this tendency to have a strong sense of purpose and self-control was noted largely as regards coping with stressful situations (Lee-Baggley et al., 2005), but rarely in connection with their negative cognitive appraisal (cf. Penley \& Tomaka, 2002). Our study shows that women who tend to be organized and self-disciplined (Costa \& McCrae, 1992a) experienced and recalled less labor pain, which may be due to their task-oriented approach to difficult situations. The findings require replication, but they seem to indicate a positive role of conscientiousness not only in the context of job performance (Barrick \& Mount, 1991), family-work conflicts (Bruck \& Allen, 2003), health status (Hampson, Goldberg, Vogt, \& Dubanowski, 2007), and stress-related changes in health behaviors (O'Connor, Conner, Jones, McMillan, \& Ferguson, 2009), but also as regards perception of childbirth and labor pain severity.

The effects of conscientiousness and neuroticism on experienced labor pain at admission (C) and on recalled labor pain $(\mathrm{C}, \mathrm{N})$ were also confirmed in bootstrapping analyses. Determination and being self-disciplined were found to lead to increased challenge appraisal, which in turn resulted in decreased actual pain. The effect of neuroticism and conscientiousness on recalled pain, when controlling for pain at T1, was found to be mediated by threat/loss appraisal. Relationships of neuroticism with negative cognitive appraisal were reported in earlier studies (Penley \& Tomaka, 2002; Schneider, 2004). This trait understood as psychological readiness to perceive threat manifests itself under conditions of increasing emotionally relevant information (Schneider, 2004), which undoubtedly corresponds to the situation of childbirth and intensifying labor pain. The results revealed that the higher the scores on neuroticism were, the higher the level of threat appraisal was, increasing in turn the experience of actual and recalled pain. This result is consistent with other findings showing that greater anxiety sensitivity was associated with a stronger tendency to appraise pain as threatening and with greater severity of recalled labor pain than that reported during labor (Curzik \& Jokic-Begic, 2011). It should be noted that along with pain intensification at admission, negative cognitive appraisal became a significant mediator for the effects of these two personality traits. It is worth mentioning that in the presented mediation models only direct and indirect effects of a specific personality dimension were taken into account, while the remaining personality traits were not included in the analyses as covariates. The inclusion of all the traits in the model yielded non-significant effects.

Our research including childbirth perception belongs to a group of studies that explore women's expectations of labor and the influence of their expectations on childbirth experiences and childbirth satisfaction (Ayers \& Pickering, 2005; van Bussel, Spitz, \& Demyttenaere, 2010; Christiaens, Verhaeghe, \& Bracke, 2008; Congdon, Adler, Epel, Laraia, \& Bush, 2016). The reported findings show the importance of cognitive appraisal in shaping perceived intensity of labor pain, which corroborates the role of cognitive mechanisms (cf. Shiloh, Mahlev, Dar, \& Ben-Rafael, 1998) in pain (Arntz \& Claassens, 2004). While the effect of negative perceptions on labor pain (Lang et al., 2006) or on general acute pain (Arntz \& Claassens, 2004) had been demonstrated in earlier studies, the finding suggesting that positive appraisal of labor reduces the labor pain seems promising and useful in clinical practice. Such positive appraisal of childbirth can be promoted in prenatal classes, and trained with the help of relatives and friends, or even by midwives during childbirth. Presumably, experienced painfulness of labor might be reduced through diverting attention from qualitative aspects of pain and positive attitudes toward childbirth, shaped by providing information about the biological process and the abilities to control pain (Ayers \& Pickering, 2005). Obviously, this would require empirical corroboration. Moreover, it is important to conduct prenatal screening for negative labor appraisal in order to target interventions at the group of women who potentially might experience greater labor pain as well as at those who have had more negative birth experiences (Congdon et al., 2016).

Surprisingly, there was no significant relationship between extraversion and cognitive appraisal, particularly challenge appraisal (Schneider, 2004). This trait involving an energetic approach towards the world and the need for companionship should bring beneficial effects in difficult situations (Schneider et al., 2011). However, research findings concerning extraversion are inconsistent, and in earlier studies this trait was found to be unrelated to cognitive appraisal (Penley \& Tomaka, 2002). A feasible explanation of the results would refer to the role of extraversion in coping with stress, where this trait is manifested first and foremost in behavioral responses depending on the type of adversity (Lee-Baggley et al., 2005). Moreover, the role of biopsychosocial variables, i.e. the number of childbirths (Ayers \& Pickering, 2005; 
Alves, Zakka, Teixeira, Siqueira, \& Siqueira, 2009), delivery type (natural/caesarean section) and childbearing women's age (Zasloff et al., 2007), was not corroborated in the study, which may result from the small sample size.

However, this study is not without limitations. Firstly, the sample size was small. Additionally, due to ethical reasons the pain experienced at the second stage of labor was recalled 2 days postpartum. This is reported as a common practice, and some results have suggested that the memory of the second stage pain was more accurately recalled than first stage pain (e.g. Niven \& Murphy-Black, 2000), while another study suggested that the labor pain was remembered as being more intense (Algom \& Lubel, 1994). Therefore, the pain perception obtained after the childbirth should be interpreted cautiously.

Moreover, also the personality assessment was conducted postpartum, again due to ethical reasons, as the 60-item version of NEO-FFI was used. On the other hand, in a longitudinal study of a large cohort, no effect of childbirth on change in the Big Five personality traits was found (when controlling for the respondents' gender) (Specht, Egloff, \& Schmukle, 2011). Further limitations of the presented study include variables not taken into account in the study design, but potentially affecting labor appraisal and pain, e.g. the use of analgesics during labor, prenatal class attendance, type of childbirth (with or without a doula) and its duration.

Summing up, the findings confirmed the relationships between neuroticism, conscientiousness, cognitive appraisal and labor pain and its recall. Neuroticism and threat/loss appraisal increased pain experienced and its memory, while conscientiousness and challenge appraisal were associated with lower intensities of actual and recalled pain. The tested mediation models clearly confirmed the effect of neuroticism on increased recalled second stage pain (T2), mediated by negative cognitive appraisal. This means that increased pain recall after childbirth supposedly related to an increasingly stressful context revealed the impact of personality on this noxious experience. Less univocal was the indirect effect of conscientiousness on labor pain via cognitive appraisal. The findings seem to have practical implications, since they suggest that reinforcement of positive attitudes towards childbirth may reduce labor pain.

\section{ENDNOTE}

1 To learn about between-group differences (primiparous vs. multiparous women; natural childbirth vs. cesarean section) the indicators of cognitive appraisal and pain were compared with oneway ANOVA. Primiparous women did not differ in indicators of cognitive appraisal (threat/loss: $M_{\mathrm{p}}=2.25, M_{\mathrm{m}}=2.21, F(1,42)=0.04, p=.845$; challenge: $\left.M_{\mathrm{p}}=2.93, M_{M}=2.66, F(1,42)=2.00, p=.164\right)$ and all three type of labor pain (actual: $M_{\mathrm{p}}=8.82$, $M_{M}=8.27, F(1,42)=2.03, p=.161$; expected: $M_{\mathrm{P}}=4.91, M_{M}=4.82, F(1,42)=0.02, p=.892 ; \mathrm{re}-$ called second stage labor pain $M_{\mathrm{p}}=9.05, M_{\mathrm{m}}=8.77$, $F(1,42)=0.51, p=.477)$ as compared to multiparous women. Women who underwent cesarean section also did not differ in all indicators from those who had normal vaginal delivery: cognitive appraisal (threat/loss: $M_{\mathrm{CS}}=2.13, M_{\mathrm{VD}}=2.24$, $F(1,42)=0.22, p=.644$; challenge: $M_{\mathrm{CS}}=3.16$, $\left.M_{\mathrm{VD}}=2.72, F(1,42)=2.96, p=.093\right)$ and all three types of labor pain (actual: $M_{\mathrm{CS}}=7.86$, $M_{\mathrm{VD}}=8.68, F(1,42)=2.47, p=.123$; expected $\mathcal{M}_{\mathrm{CS}}=5.29$, $M_{\mathrm{vD}}=4.78, F(1,42)=0.31, p=.581$; recalled second stage labor pain $M_{\mathrm{CS}}=8.57, M_{\mathrm{VD}}=8.97, F(1,42)=0.60$, $p=.444)$.

\section{References}

Algom, D., \& Lubel, S. (1994). Psychophysics in the field: perception and memory for labor pain. Perception \& Psychophysics, 55, 133-141.

Alves, B., Zakka, A. B., Teixeira, T., Siqueira, M. J., \& Siqueira, J. T. T. (2009). Evaluation of pain before and after vaginal delivery. Clinical And Experimental Obstetrics \& Gynecology, 36, 241-244.

Arntz, A. (1996). Why do people tend to overpredict pain? On the asymmetries between underpredictions and overpredictions of pain. Behaviour Research and Therapy, 34, 545-554.

Arntz, A., \& Claassens, L. (2004). The meaning of pain influences its experienced intensity. Pain, 109, 20-25.

Ayers, S., \& Pickering, A. D. (2005). Women's expectations and experience of birth. Psychology and Health, 20, 79-92.

Barrick, R. M., \& Mount, K. M. (1991). The big five personality dimensions and job performance: A meta-analysis. Personnel Psychology, 44, 1-26.

Blascovich, J., Seery, M. D., Mugridge, C. A., Norris, R. K., \& Weisbuch, M. (2004). Predicting athletic performance from cardiovascular indexes of challenge and threat. Journal of Experimental Social Psychology, 40, 683-688.

Brown, A., \& Johnston, R. (2013). Maternal experience of musculoskeletal pain during pregnancy and birth outcomes: significance of lower back and pelvic pain. Midwifery, 29, 1346-1351.

Bruck, C. S., \& Allen, T. D. (2003). The relationship between big five personality traits, negative affectivity, type A behavior and work family conflict. Journal of Vocational Behavior, 63, 457-472.

van Bussel, J. C. H., Spitz, B., \& Demyttenaere, K. (2010). Childbirth expectations and experiences
Personality, cognitive appraisal and labor pain 
and associations with mothers' attitudes to pregnancy, the child and motherhood. Journal of Reproductive and Infant Psychology, 28, 143-160.

Chandler, M., Kennedy, P., \& Sandhu, N. (2007). The association between threat appraisals and psychological adjustment in partners of people with spinal cord injuries. Rehabilitation Psychology, 52, 470-477.

Christiaens, W., Verhaeghe, M., \& Bracke, P. (2008). Childbirth expectations and experiences in Belgian and Dutch models of maternity care. Journal of Reproductive and Infant Psychology, 26, 309-322.

Kwissa-Gajewska, Magdalena Dołęgowska

Congdon, J. L. , Adler, N. E., Epel, E. S., Laraia, B. A., \& Bush, N. R. (2016). A prospective investigation of prenatal mood and childbirth perceptions in an ethnically diverse, low-income sample. Birth: Issues in Perinatal Care, 43, 159-166.

Costa, P. T., Jr., \& McCrae, R. R. (1992a). Four ways five factors are basic. Personality \& Individual Difference, 13, 653-665.

Costa, P. T., \& McCrae, P. R., Jr. (1992b). Revised NEO Personality Inventory (NEO PI-R) and NEO Five-Factor Inventory (NEO-FFI) professional manual. USA: Psychological Assessment Resources, Inc.

Curzik, D., \& Jokic-Begic, N. (2011). Anxiety sensitivity and anxiety as correlates of expected, experienced and recalled labor pain. Journal of Psychosomatic Obstetrics and Gynecology, 32, 198-203.

Eysenck, S. B. (1961). Personality and pain assessment in childbirth of married and unmarried mothers. The British Journal of Psychiatry, 107, 417-430.

Goubert, L., Crombez, G., \& Van Damme, S. (2004). The role of neuroticism, pain catastrophizing and pain-related fear in vigilance to pain: A structural equations approach. Pain, 107, 234-241.

Gunthert, K. C., Cohen, L. H., \& Armeli, S. (1999). The role of neuroticism in daily stress and coping. Journal of Personality and Social Psychology, 77, 1087-1100.

Guszkowska, M. (2014). The effect of exercise and childbirth classes on fear of childbirth and locus of labor pain control. Anxiety, Stress, \& Coping, 27, 176-189.

Hampson, S. E., Goldberg, L. R., Vogt, T. M., \& Dubanoski, J. P. (2007). Mechanisms by which childhood personality traits influence adult health status: Educational attainment and healthy behaviors. Health Psychology, 26, 121-125.

Hayes, A. F. (2013). Introduction to mediation, moderation, and conditional process analysis. New York: The Guilford Press.

Johnston, R. G., \& Brown, A. E. (2013). Maternal trait personality and childbirth: the role of extraversion and neuroticism. Midwifery, 11, 1244-1250.

Lang, A. J., Sorrell, J. T., Rodgers, C. S., \& Lebeck, M. M. (2006). Anxiety sensitivity as a predictor of labor pain. European Journal of Pain, 10, 263-270.

Lazarus, R. S. (1991). Progress on a cognitive-motivational-relational theory of emotion. American Psychologist, 46, 819-834.

Lazarus, R. S., \& Folkman, S. (1984). Stress, appraisal, and coping. New York: Springer.

Lee-Baggley, D., Preece, M., \& DeLongis, A. (2005). Coping with interpersonal stress: Role of Big Five traits. Journal of Personality, 73, 1141-1180.

Lefebvre, J. C. \& Keefe, F. J. (2013). The effect of neuroticism on the recall of persistent low-back pain and perceived activity interference. The Journal of Pain, 14, 948-956.

Lynn, R., \& Eysenck, H. J. (1961). Tolerance for pain, extraversion and neuroticism. Perceptual and Motor Skills, 12, 161-162.

Maples, J. P., Guan, L., Carter, N. T., \& Miller, J. D. (2014). A test of the International Personality Item Pool representation of the Revised NEO Personality Inventory and development of a 120-item IPIP-based measure of the five-factor model. Psychological Assessment, 26, 1070-1084.

McCrae, R. R. (1990). Controlling neuroticism in the measurement of stress. Stress \& Medicine, 6, 237-241.

McGowan, J., Gardner, D., \& Fletcher, R. (2006). Positive and negative affective outcomes of occupational stress. New Zealand Journal of Psychology, 35, 92-98.

Melzack, R. (1993). Pain: Past, present and future. Canadian Journal of Experimental Psychology/Revue Canadienne de Psychologie Expérimentale, 47, 615-629.

Melzack, R. (2001). Pain and the neuromatrix in the brain. Journal of Dental Education, 65, 1378-1382.

Melzack, R., \& Katz, J. (2004). The gate control theory: Reaching for the brain. In T. Hadjistavropoulos \& K. D. Craig (eds.), Pain: Psychological Perspectives (pp. 13-34). Mahwah, NJ: Lawrence Erlbaum Associates.

Melzack, R., \& Wall, P. D. (1965). Pain mechanisms: A new theory. Science, 150, 971-979.

Niven, C. A., \& Murphy-Black, T. (2000). Memory for labor pain: a review of the literature. Birth, 27, 244-253.

O’Connor, D. B., Conner, M., Jones, F., McMillan, B., \& Ferguson, E. (2009). Exploring the benefits of conscientiousness: an investigation of the role of daily stressors and health behaviors. Annals of Behavioral Medicine, 37, 184-196.

Payne, L., Seidman, L. C., Lung, K. C., Zelter, L. K., \& Tsao, J. C. (2013). Relationship of neuroticism and laboratory pain in healthy children: does anxiety sensitivity play a role? Pain, 154, 103-109.

Pearce, S., \& Porter S. (1983). Personality variables and pain expectations. Personality and Individual Differences, 4, 559-561.

Penley, J. A., \& Tomaka, J. (2002). Associations among the Big Five, emotional responses, and coping 
with acute stress. Personality and Individual Differences, 32, 1215-1228.

Preacher, K. J., \& Hayes, A. F. (2008). Asymptotic and resampling strategies for assessing and comparing indirect effects in multiple mediator models. Behavior Research Methods, 40, 879-891.

Ramírez-Maestre, C., Martínez, A. E. L., \& Zarazaga, R. E. (2004). Personality characteristics as differential variables of the pain experience. Journal of Behavioral Medicine, 27, 147-165.

Raselli, C., \& Broderick, J. E. (2007). The association of depression and neuroticism with pain reports: A comparison of momentary and recalled pain assessment. Journal of Psychosomatic Research, 62, 313-320.

Ruffle, J. K., Farmer, A. D., Kano, M., Giampietro, V., Aziz, Q., \& Coen, S. J. (2015). The influence of extraversion on brain activity at baseline and during the experience and expectation of visceral pain. Personality and Individual Differences, 74, 248-253.

Saisto, T., Salmela-Aro, K., Nurmi, J. E., \& Halmesmäki, E. (2001). Psychosocial predictors of disappointment with delivery and puerperal depression. Acta Obstetricia et Gynecologica Scandinavica, 80, 39-45.

Schneider, T. (2004). The role of Neuroticism on psychological and physiological stress responses. Journal of Experimental Social Psychology, 40, 795-804.

Schneider, T., Rench, T. A., Lyons, J. B., \& Riffle, R. R. (2011). The influence of neuroticism, extraversion and openness on stress responses. Stress and Health, 28, 102-110.

Shiloh, S., Mahlev, U., Dar, R., \& Ben-Rafael, Z. (1998). Interactive effects of viewing a contraction monitor and information-seeking style on reported childbirth pain. Cognitive Therapy and Research, 22, 501-516.

Shrout, P. E., \& Bolger, N. (2002). Mediation in experimental and nonexperimental studies: New procedures and recommendations. Psychological Methods, 7, 422-445.

Simkin, P. (2000). Commentary: the meaning of labor pain. Birth, 27, 254-255.

Specht, J., Egloff, B., \& Schmukle, S. C. (2011). Stability and change of personality across the life course: The impact of age and major life events on mean-level and rank-order stability of the Big Five. Journal of Personality and Social Psychology, 101, 862-882.

Taylor, S. E. (2012). Health Psychology (8 $8^{\text {th }}$ ed.). New York: McGraw-Hill.

Terry, R., \& Gijsbers, K. (2000). Memory for the quantitative and qualitative aspects of labour pain: a preliminary study. Journal of Reproductive and Infant Psychology, 18, 143-152.

Vassend, O., Røysamb, E., \& Nielsen, C. (2013). Five-factor personality traits and pain sensitivity: A twin study. Pain, 154, 722-728.
Wade, J. B., Dougherty, L. M., Hart, R. P., Rafii, A., \& Price, D. D. (1992). A canonical correlation anal$y$ sis of the influence of neuroticism and extraversion on chronic pain, suffering, and pain behavior. Pain, 51, 67-73.

Waldenström, U. (2003). Women's memory of childbirth at two months and one year after the birth. Birth, 30, 248-254.

Waldenström, U., \& Schytt, E. (2009). A longitudinal study of women's memory of labour pain - from 2 months to 5 years after the birth. British Journal of Obstetrics and Gynaecology, 116, 577-583.

Watson, D., \& Pennebaker, J. W. (1989). Health complaints, stress, and distress: Exploring the central role of negative affectivity. Psychological Review, 96, 234-254.

Włodarczyk, D., \& Wrześniewski, K. (2010). Kwestionariusz Oceny Stresu [The Stress Appraisal Questionnaire]. Przegląd Psychologiczny, 53, 479496.

Zasloff, E., Schytt, E., \& Waldenström, U. (2007). First time mothers' pregnancy and birth experiences varying by age. Acta Obstetricia et Gynecologica Scandinavica, 86, 1328-1336.
Personality, cognitive appraisal and labor pain 